\title{
Anseios de progresso: as decisões da câmara municipal de Alfenas-MG para transformar a paisagem urbana e os costumes locais durante a Primeira República
}

Longings of progress: the decisions of the municipal council of Alfenas-MG to transform the urban landscape and local customs during the First Republic

Alisson Eugênio*

\section{Resumo}

Ao longo deste artigo serão analisadas as decisões da Câmara Municipal de Alfenas (por meio de leis aprovadas pelos seus membros) para transformar a paisagem e os costumes locais durante a Primeira República, com o objetivo de mostrar que as elites políticas hegemônicas do município procuraram intervir na cidade e em determinadas práticas de seus habitantes, a fim de adequá-las ao ideal de progresso em voga no Ocidente desde o Iluminismo. Assim, será mostrado que no interior do país, e mesmo em municípios sustentados na economia agropastoril, determinadas iniciativas consideradas modernas foram colocadas em práticas, revelando que suas elites, ou parte delas, estavam sintonizadas com os ideais de modernidade.

Palavras-chave: Paisagem. Costumes. Progresso. Modernidade. Primeira República.

\begin{abstract}
Throughout this article will analyze the decisions of the City of Alfenas (through laws passed by its members) to transform the landscape and local customs during the First Republic, in order to show that the hegemonic political elites of the city They sought to intervene in the city and in certain practices of its inhabitants in order to adapt them to the ideal of progress in vogue in the West since the Enlightenment. Thus, it will be shown that within the country, and even in municipalities supported in agropastoral economy, certain modern initiatives were put into practice, revealing that their elites, or part of them, were attuned to the ideas of the modernity.
\end{abstract}

Keywords: Landscape. Customs. Progress. Modernity. First Republic.

Desde a consolidação do antropocentrismo como fundamento ideológico da forma de ver o mundo e de organizar a cultura, o saber e as sociedades, inaugurou-se uma nova era na trajetória histórica ocidental. Uma das suas maiores características é o entendimento de que o homem poderia melhorar a sua condição ao combater um conjunto de problemas (injustiça, guerra, fome, epidemias, catástrofes naturais, morte

\footnotetext{
* Doutor em História Econômica pela Universidade de São Paulo (USP) e Pós-doutor em História pela Universidade Federal de Minas Gerais (UFMG). Professor da Universidade Federal de Alfenas (UNIFAL).
} 
precoce, etc.) por meio da razão e das suas irmãs siamesas: a ciência e a educação (Ilha da Utopia, 1516, de Thomas Morus e Nova Atlântida, 1627, de Francis Bacon são indicadores literários disso). Esse entendimento emerge de uma conturbada situação histórica marcada pelas crises responsáveis pelo colapso da época medieval e, em meio a elas, da reconfiguração do quadro filosófico até então fundamentado na teologia cristã expressa no teocentrismo. Com o expansionismo marítimo, do qual derivou a exponencial ampliação das relações de trocas, e a Reforma, que contribuiu decisivamente para a abertura das possibilidades de afirmação da individualidade (expressa na máxima cartesiana "penso logo existo"), aos poucos uma nova consciência histórica (oriunda do entendimento acima definido), que estava sendo construída (principalmente por intelectuais identificados com o humanismo) nos meios cultos da Europa a partir do Renascimento, foi se afirmando. Esse turbilhão de ideias e acontecimentos acabaram, após um complexo movimento dialético, culminando em uma nova época batizada de Idade Moderna, porque diversas inovações foram experimentadas: 1) no âmbito institucional, surgiram os Estados com poder central e monopólio da força, 2) no âmbito econômico, a produção voltava-se cada mais para a satisfação do mercado, 3) no âmbito social, a afirmação do indivíduo e, com ela, a valorização da educação, 4) no âmbito do conhecimento, o empirismo começa a superar a tradição como lastro do saber, 5) no âmbito da cultura, a proliferação de livros impressos, possibilitada com a invenção da imprensa e com a afirmação das línguas nacionais, ampliou a difusão do conhecimento. Embora muita coisa tivesse continuado como sempre esteve anteriormente, isto é, apesar das permanências da época medieval, muitas delas incômodas para as mentes mais críticas e ansiosas por mudanças, um novo tempo se abria no horizonte; um tempo movimentado por grandes expectativas, sobretudo para aquelas pessoas, minoria consciente de sua época, que desejava um mundo melhor (BURKE, 2003; HOBSBAWN, 2003; CASSIRER, 1994; HELLER, 1982; HAZARD, 1973; GUSDORF, 1972).

A esse movimento, durante o Iluminismo, deu-se no nome de progresso, o qual na Enciclopédia de Diderot e D’Alembert "significa marcha para frente" (DIDEROT; D'ALEMBERT, 1769, p. 347). Com esse mesmo significado, ele é apresentado no Grande dicionário universal do século XIX como a vitória "da civilização sobre a barbárie, da ciência sobre a ignorância, da liberdade sobre o despotismo, da riqueza sobre a miséria e do bem sobre o mal". Essa ideia que para uns, como Bury (2004), é apenas um instrumento de compreensão do mundo, e para outros, como Nisbet (1980), é 
um elemento inerente às sociedades dominou, ao ponto de ser transformado em um mito, a consciência ocidental até o final da Segunda Guerra Mundial, funcionando como uma ideologia para as elites justificarem, por meio da ciência e da técnica, suas proposições reformistas como se estivessem conduzindo a humanidade a um futuro desejável.

O devir histórico, então, teria como marca esse movimento, em cuja trajetória haveria, no julgamento dos próceres daquela nova consciência, uma sucessão de rupturas com determinados legados do passado, considerados por eles sinônimos de atraso. Assim, a marcha para frente seria impulsionada pela dialética entre o antigo e o moderno, em uma dinâmica instauradora da modernidade. Esta, uma das ideias mais imprecisas e, ao mesmo tempo, impactante em relação à forma de conceber e agir no mundo com a consolidação da sociedade industrial, tornou-se uma espécie de atestado de progresso, porque ela expressa, antes de tudo, a vontade de se inaugurar um futuro novo (GUMBRECHT, 1992). Dessa maneira, pode ser entendida, de acordo com Habermas, como um momento do pensamento humano, da sua vontade de reorientar a história a partir de uma nova forma de ver o passado formada a partir do Renascimento (HABERMAS, 2002, p. 3-33). Em outras palavras, trata-se de uma categoria de interpretação construída, segundo Agnes Heller, desde o final do período medieval, que acabou sendo transformada em uma ideologia, a partir da qual as elites fundamentaram seus projetos de modernização, isto é, de superação de elementos do passado considerados por elas entraves ao progresso (HELLER, 1999, p. 15).

Se, por um lado, a modernidade é um estado da consciência, uma ideologia, por outro, conforme diversos autores, como Marhall Berman, ela é, também, pensada como fenômeno, que teria sido impulsionado a partir de meados do século XV e incrementado por um conjunto de acontecimentos históricos, sobretudo a Revolução Industrial e a Revolução Francesa. Dessa maneira, ela apresenta uma essência ambígua, pois, em primeiro lugar, a sua ação criadora é destruidora, porque "nos despeja num turbilhão de permanente desintegração e mudança", afinal, "ser moderno é fazer parte de um universo no qual, como disse Marx, tudo o que é sólido desmancha no ar" (BERMAN, 1986, p. 15). Em segundo lugar, fundada na razão prática, ela provocou, segundo Adorno e Horkheimer, um vazio espiritual que, ao ser preenchido pelos valores do mercado, permitiu a escalada de barbáries inaceitáveis para a dignidade humana, como o Holocausto e a bomba de Iroshima e Nagasaki. E, por fim, no plano social, à sombra das surpreendentes e sofísticadas novidades técnicas, concentradas em certas ilhas de 
prosperidade, a miséria e todos os seus subprodutos formaram um imenso oceano de sofrimento (ADORNO; HORKHEIMER, 1985).

Seja como fenômeno, ou como uma ideia, uma consciência do mundo, uma categoria de interpretação e, sobretudo, como um atestado de progresso, a modernidade passou a ser uma referência essencial para os projetos de reforma orquestrados, desde a era das revoluções, pelas elites dirigentes de diversas sociedades. Há diversos estudos que mostram como o reformismo modernizante ocorreu pelo planeta, alterando as paisagens e os costumes de uma maneira tão rápida ao ponto de os indivíduos não reconheceram, em menos de uma geração, o mundo à sua volta, como afirma Sevcenko (1992, p. 162): "Inovações tecnológicas invadindo o cotidiano num surto inédito, multiplicando-se mais rapidamente do que as pessoas pudessem se adaptar e as elas corroendo os últimos resquícios de um mundo estável."

Todavia, como a historiografia sobre esse assunto privilegia os grandes centros urbanos, fica a impressão de que os municípios afastados das metrópoles, e ainda dominados pela economia rural, ficaram à margem desse processo histórico. Isso não é totalmente verdade, pois há exceções. Uma delas, Alfenas, será analisada neste artigo, cuja trajetória histórica durante a primeira experiência republicana brasileira será utilizada para mostrar que as elites políticas de alguns municípios do interior de países com as características do Brasil das décadas iniciais do século XX estavam sintonizadas com a ideia de progresso e com os anseios de modernidade dela advindos. Para isso, será usada a documentação produzida pela sua Câmara Municipal, especialmente as leis que revelam o empenho de seus membros para reformar a cidade e adequar a sua paisagem e os costumes dos seus habitantes aos ideais da vida moderna.

Seguindo a tradição teórica formulada a partir da teoria da ação social weberiana, as decisões do legislativo serão aqui compreendidas como ações culturalmente orientadas e destinadas a atingir determinados fins. Para isso, o conceito de cultura formulado por Clifford Geertz será muito útil, uma vez que, de acordo com tal autor, "acreditando, como Max Weber, que o homem é um animal amarrado a teias de significados que ele mesmo teceu," ele assume "a cultura como sendo essas teias". Desse modo, a cultura é considerada um contexto, algo dentro do qual a ação humana, em suas mais diversas manifestações, pode ser compreendida como um signo, cujo significado depende das suas conexões com o contexto no qual está inserida, com as motivações que a impulsionaram, com a multiplicidade de estruturas que possibilitaram a sua ocorrência e com o objetivo almejado (GEERTZ, 1978, p. 15.). Em outras 
palavras, a legislação destinada à reforma urbana dependeu, além das oportunidades abertas pelo avanço das forças produtivas e da consolidação do capitalismo, também da formação de uma nova consciência, a qual será doravante identificada como ideologia do progresso (a da capacidade humana de dirigir o rumo da história e romper com o passado para atingir um futuro desejável) que possibilitou a construção de novos valores culturais, dos quais derivam novos comportamentos e novos interesses.

Como a eficácia das leis depende da sua repercussão no cotidiano, as reflexões de Agnes Heller sobre esse tema serão igualmente úteis a essa pesquisa. Segundo ela, a vida cotidiana encontra-se "no centro do acontecer histórico", tornando-se assim "a verdadeira essência da substância social", pois "as grandes ações não cotidianas contadas nos livros de história partem da vida cotidiana e a ela retornam", e o seu caráter histórico somente assim pode ser considerado "graças ao seu posterior efeito na cotidianidade". Em outras palavras, o cotidiano é uma temporalidade estruturada, pois as ações rotineiras que marcam o dia a dia das sociedades são resultado dos seus movimentos estruturais. Mas ele também é estruturante, pois é nele também que a estruturação que dá sentido à vida diária é modificada, reestruturada, como resultado dos efeitos imprevistos da sua própria dinâmica, ou da possibilidade de os indivíduos tomarem consciência das oportunidades histórias e agir para aproveitá-las (HELLER, 1985, p. 20). Dito de outra forma, as decisões legislativas, destinadas a modernizar o meio urbano e a vida social, precisam ser assimiladas pelos indivíduos para provocar os impactos cotidianos que, em seu conjunto, são capazes de transformar as estruturas das sociedades e o comportamento humano.

Em síntese, as proposições teóricas de Agnes Heller e Clifford Geertz contribuirão, respectivamente, para entender o cotidiano como temporalidade estruturada e estruturante e a cultura como contexto que dá sentido às ações, no caso deste artigo, a reconfiguração paisagística da cidade e dos comportamentos dos seus habitantes, para adequar o município de Alfenas aos novos valores culturais (planejamento urbano, controle da população, higiene pública, educação, etc.) que caracterizavam o mundo moderno e, dessa maneira, impulsionar o progresso da sociedade local.

O município, que será a seguir analisado com base nas considerações teóricas acima apresentadas, está situado no sul de Minas Gerais, em uma enorme rede urbana formada entre três grandes regiões metropolitanas: São Paulo, Rio de Janeiro e Belo Horizonte. Sua formação econômica está ligada, nos primórdios da colonização, à 
dilatação demográfica paulista e ao incremento das atividades auríferas e, em um segundo momento, às oportunidades abertas pela reorientação econômica mineira ocorrida na segunda metade do século XVIII após a crise do ouro.

Seus primeiros colonizadores foram proprietários rurais que buscavam terras para o cultivo de alimentos para subsistência e para os mercados vicinais de uma região então em expansão. A transformação da capital do país em sede da corte portuguesa, inicialmente, e o crescimento da cafeicultura no oeste paulista, posteriormente, ampliaram os horizontes econômicos da elite local. Esta aproveitou as oportunidades abertas por esses fatores para impulsionar a produção de gêneros de primeira necessidade, cada vez mais demandados pelos municípios especializados na monocultura cafeeira, de cuja rede urbana Alfenas fazia parte, o que lhe proporcionou um acúmulo de capital fundamental para alavancar a sua produção agropastoril (LENHARO, 1979; SAES, 2012).

O incremento da sua economia rural, junto com os anseios de progresso da sua elite política, criou no município as condições para um surto de modernização que, no Brasil, sabe-se que foi conservadora, pois a transformação estrutural pela qual sua sociedade estava vivenciando desde o fim da guerra contra o Paraguai não afetou a sua hierarquia social, pois a nova forma de governo adotada em 1889, inaugurada por um processo histórico iniciado com a crise do Império, foi oriunda de uma cisão da classe dominante. Uma nova aristocracia substituía outra no comando do poder, com o apoio dos militares, enquanto o povo assistia a tudo "bestializado". Tratava-se de uma transição pelo alto, sem participação das camadas populares. Afinal, o que estava em jogo era o interesse da nova elite econômica, a qual se empenhou na construção de um novo pacto político, conhecido como pacto oligárquico (sustentado na política do café com leite no nível federal, na política dos governadores no nível estadual e no coronelismo no nível municipal) para controlar a máquina do Estado e proteger seus interesses de classe. $\mathrm{O}$ estado liberal, originado desse pacto, não contemplou a grande massa da população que continuou entregue à sua própria sorte, ou ao que sobrou da sensibilidade religiosa, expressa na caridade pública, ou à dádiva dos protagonistas da situação política local, ancorada no paternalismo agora na sua manifestação coronelista.

Por esses motivos, as transformações no universo das relações econômicas não foram revolucionárias, pois a macroeconomia da Primeira República ainda estava estruturada nos moldes da economia colonial. Grande parte do seu setor produtivo estava orientada para exortação de produtos primários, em especial o café. 
Consequentemente, importava-se quase tudo em relação ao consumo de mercadorias industriais, sobretudo os bens duráveis e bens de capital, já que sua incipiente indústria somente era capaz de produzir basicamente bens de consumo imediato, como tecidos, calçados, chapéus, enlatados, bebidas, etc. (FURTADO, 2000; PRADO Jr, 1995).

Isso não quer dizer que apenas nas áreas especializadas na cafeicultura houve um surto modernizador, pois era possível acumular capital a partir de atividades econômicas voltadas para o abastecimento interno, cuja dinâmica, dotada de um ritmo próprio, tinha condições de gerar riqueza de forma independente do setor exportador nos quadros da economia colonial. A formação econômica alfenense é um exemplo disso.

É nesse contexto que as leis da Câmara Municipal local destinadas a alterar a paisagem da cidade e os costumes de seus habitantes foram criadas. Em relação ao primeiro alvo a sofrer alterações, buscava-se no município, seguindo as tendências históricas de outros espaços urbanos, dotar a sede municipal de uma feição moderna. Para isso, uma série de medidas foi adotada. A mais antiga encontrada na documentação, datada no dia 6 de julho de 1898, autorizou "o agente executivo a fazer passeios em frente aos prédios da cidade, nas ruas principais, cobrando-se depois dos proprietários a metade da despesa" e, no ano seguinte, em votação ocorrida no dia 7 de abril, ele foi "autorizado a substituir a iluminação pública de querosene pela de gás acetileno". Já no ano de 1901, no dia 20 de outubro, o legislativo local criou normas para restringir o comércio ambulante de alimentos nas ruas e concentrá-lo no mercado público. Assim, seus membros definiram, sob a forma da lei, que, sendo os "mercados estabelecimentos públicos destinados a transações principalmente de gêneros alimentícios", e sendo ele "o centro de comércio de gêneros alimentícios, fica proibida a venda dos mesmos nas ruas da cidade, exceto verduras, frutas, ovos, pães e leite." Dois anos depois, no dia 10 de junho de 1903, foi "o agente executivo autorizado a desapropriar, amigável ou judicialmente, as casas ou parte delas e respectivos terrenos pertencentes a José Teodoro de Mello e a José do Rosário Velano, a fim de ser alargada a Rua Sete de Abril e, no mesmo ano, no dia 25 de outubro, foram estabelecidas, por meio de um regulamento extenso, as condições para a prática da mendicância. Em relação a isso, começaram a regulamentação identificando seus praticantes: "Todo aquele indivíduo que não puder ganhar a vida pelo trabalho e que não tiver meios nem parentes em condições de lhe prestar alimentos, nos termos da lei civil, e explorar esmolas, será considerado mendigo". Este, para estender a mão à caridade pública, 
precisava pedir uma licença à Câmara a qual somente era concedida após exame, elaborado pela autoridade policial e médica, que declarasse "a pessoa incapaz de ganhar a vida pelo trabalho, após ter averiguado se a pessoa não" possuía "meio de fortuna algum e nem parentes com obrigação legal de sustentá-la" e se era "natural do município" ou tivesse "família constituída aqui há mais de dois anos"; caso contrário, deveria "ser remetido à sede de sua naturalidade." Aqueles que fossem aprovados em tal investigação portariam "uma placa com a designação mendigo e um número de inscrição para trazer no peito de forma bem legível". Além disso, nenhum deles poderia "pedir esmola [...] exibindo chagas, feridas ou deformidades."

Pelo que se observa, houve um esforço para "limpar" a cidade de elementos que as elites modernizantes consideravam arcaicos, pois, para elas, os espaços urbanos modernos exigiam passeios, luz a gás acetileno (uma década depois substituída pela elétrica), ruas largas e com a menor poluição visual possível de vendedores ambulantes de alimentos e de mendigos. Em relação a esses, aquela tradicional sensibilidade caritativa em relação à extrema pobreza alheia (que experimentou seu auge na Idade Média, quando a pobreza material não era vista como sinônimo do fracasso pessoal), há muito tempo vinha se desmanchando no ar com a consolidação do capitalismo, da sociedade liberal e dos valores de mercado.

Nesse novo tempo, estruturado por um liberalismo excludente, por uma modernização conservadora e por uma prosperidade concentrada os indivíduos, sistematicamente empurrados para a miséria, por não terem sido assimilados pelo processo modernizador, passaram a ser vistos como uma espécie de "resíduos prémodernos" (isto é, uma espécie de subcidadãos, entregues à sua própria sorte, à solidariedade das sociedades beneficentes, à dádiva coronelista e ao que sobrou do antigo sentimento de caridade).

A ânsia pela novidade, pela modernidade, pelo futuro, não parou por aí. Outras medidas foram tomadas pela Câmara para reconfigurar a Alfenas da Velha República. Uma delas, no dia 28 de junho de 1917, autorizou o agente executivo a "fazer o ajardinamento da Praça Municipal", e, no dia seguinte, a "promover o abarruamento e a macadamização" da mesma Praça e de diversas ruas centrais (do Comércio, Cônego José Carlos, Direita e Pedra Branca). Alguns anos depois, no dia 23 de janeiro de 1920, o legislativo local instituiu "o prêmio de duzentos mil réis para todo alqueire de terreno reflorestado com [...] pinho, eucalipto, cedro, jacarandá e jequitibá vermelho", advertindo, porém que não teria "direito ao prêmio o proprietário cujo terreno não" 
estivesse "ao menos com a metade coberto de árvores de quatro a cinco anos de idade". No ano seguinte, considerou ser "de utilidade pública, a demolição de prédios [...] por estarem mal alinhados, ou nivelados, ou ameaçarem ruína, ou por serem irremediavelmente insalubres". Procuraram, também, tomar providências sanitárias, como a setorização de determinadas atividades industriais, conforme registrado em ata na votação de 3 de outubro de 1924, a partir da qual foi o "presidente da Câmara autorizado a entrar em acordo com Conrado Teff quanto à escolha do local para instalação de sua fábrica de salames e produtos similares fora do perímetro urbano e atentas às conveniências da higiene pública". Além disso, já no final da nossa primeira experiência republicana, uma lei tornou "proibido o plantio e conservação de bananeiras em toda a área compreendida no perímetro urbano", obrigou "ser extintas as existentes" e ainda determinou "igualmente proibido nos quintais da cidade o excesso de arborização, qualquer que seja ela, desde que pudesse resultar prejuízos à saúde pública”.

Assim, aos poucos, a elite política sintonizada com os ideais de progresso em voga no Ocidente desde o Iluminismo procurou modernizar a sede do município de Alfenas ao longo da Primeira República. Percebe-se que, com as leis anteriormente expostas, buscavam destruir alguns elementos do passado, em particular aqueles que se tornaram incômodos para uma mentalidade seduzida pela miragem da modernidade. Se alguns deles dependiam apenas da intervenção no espaço, como os acima citados, outros tantos, de natureza mais complexa, demandaram intervenção nos costumes; costumes praticados ancestralmente e, por essa razão, mais difícil e demorado de serem modificados.

Para a compreensão das medidas interventoras em determinados hábitos cotidianos vistos pelos próceres da modernização como expressão de atraso, é necessário explicar que um dos sentidos do progresso é a civilização, ou seja, a passagem do estado de barbárie para uma forma supostamente superior de organização social (BRAUDEL, 1985). Com esse significado, tal conceito pode ser interpretado como expressão da autoimagem que "a classe alta europeia" (e aquelas nas Américas que nela se inspiraram) forjou para si mesma um "[...] tipo de comportamento através do qual ela se sentia diferente de todos aqueles que julgava mais simples ou primitivo" (ELIAS, 1990, p. 54). Com base nesse julgamento, construído lentamente desde a Renascença, os indivíduos identificados com ele foram se afastando de determinadas práticas que, até então, eram comuns a todos, ou pelo menos aceitas coletivamente, de 
forma a abandoná-las às classes baixas. Mais do que isso, depois de terem se afastado delas, começaram a combatê-las sistematicamente (BURKE, 1995).

Essa dialética cultural, impulsionada pela onda de modernidade experimentada em certas ilhas de prosperidade na periferia do capitalismo, desde pelo menos, no caso brasileiro, a Proclamação da República, também foi promovida em algumas sociedades rurais, que fomentaram um considerável centro urbano, por frações de elites sintonizadas com a ideologia do progresso, como as de Alfenas. Com base nessa ideologia, elas idealizaram no legislativo local, por meio de um conjunto de leis, uma reforma dos costumes.

Um dos primeiros alvos dessa reforma foi a convivência, uma quase promiscuidade, no espaço urbano entre pessoas e animais que eram ainda muito úteis para a vida cotidiana. A era do carbono estava apenas começando e, por isso, os motores à combustão ainda não marcavam a paisagem no alvorecer do século. Consequentemente, o deslocamento humano e de mercadorias dependiam vitalmente de carros de boi, tropas de muares, carroças e cavalos, o que conferia um aspecto ruralizado à cidade. Para evitar alguns inconvenientes típicos de um meio social com essas características, a Câmara aprovou várias leis. Uma delas, editada no dia 26 de janeiro de 1910, determina: "É proibido amarrar animais nas árvores da arborização pública." No mesmo ano, no dia 25 de julho, proibiu "o trânsito de carro de boi na Rua do Oriente", entre a Praça Municipal e a Praça da Estação, o que foi estendido a "diversas ruas" no dia 23 de julho 1916, "excetuando-se aqueles que tiverem de levar lenha ou outros objetos às casas." No dia 25 de junho de 1914, proibiu "o trânsito de cavaleiros na praça municipal por cima dos passeios." Já em 1921, torna proibido "ter mais de 3 vacas nos quintais situados no perímetro urbano" e, em 1927 veio a radicalização final com a "proibição, no perímetro urbano, da permanência de gado vacum, não se permitindo nem mesmo a ordenha de vacas leiteiras em quintais de casas particulares."

Em seu conjunto, tais leis destinavam-se à desruralização da cidade; pois o moderno era identificado com o urbano e, desse modo, ao ser fomentado, precisava limitar ao mínimo, enquanto ainda fosse necessário nas áreas urbanizadas, os ícones de um estilo de vida que se desejava superar. Todavia, nem sempre as decisões do legislativo municipal eram acatadas sem protestos. Certa vez, no dia 22 de julho de 1912, proprietários de estabelecimentos econômicos de natureza variada enviaram um requerimento ao agente executivo Cel. José Bento Xavier de Toledo reclamando da 
dificuldade por eles vivenciada dia a dia, devido ao fato de que na Rua do Oriente estava, desde 1910, "proibido transitar carros de boi, quando a maior parte do transporte", reiteravam, "é feita nesses carros". Em resposta, obtiveram o compromisso de a municipalidade incluir no orçamento do ano seguinte a abertura de ruas para facilitar o deslocamento de pessoas, matérias primas e mercadorias nos proximidades dos requerentes.

Outro bloco de medidas destinou-se a sanear o município. Vivia-se na época o que um historiador chamou de a era do saneamento (HOCHMAN, 1998). A precariedade da higiene pública passou a ser tida pelas sociedades modernas como um dos grandes problemas cotidianos. Tanto que o Estado brasileiro, influenciado pelas suas elites médicas, já vinha tomando um conjunto de medidas, muitas delas autoritárias, para sanear alguns espaços urbanos da nação desde o tempo do Império, quando a saúde estava definitivamente sendo transformada em um bem público, após longa trajetória histórica inaugurada com o Iluminismo. Isso porque, com as Luzes, consolidou-se a visão que considera a doença um dos maiores entraves à construção de uma sociedade plenamente civilizada e da felicidade dos povos (EUGÊNIO, 2012). Daí os governos, nos seus diversos níveis, aos poucos foram inserindo o saneamento em sua agenda pública.

Em sintonia com tais postulados, os vereadores de Alfenas decidiram, no dia 25 de junho de 1911, que dessa data em diante estava "o agente executivo autorizado a promover, como" julgasse "conveniente, por conta da Câmara, a limpeza pública das ruas e praças principais da cidade”. Alguns anos mais tarde, no dia 18 de setembro de 1914, decidiram criar um regulamento para controlar o acesso às fontes de água. Com esse objetivo, determinaram: que "as nascentes serão cercadas de arame farpado e cuidadas pelo zelador de águas, para evitar a entrada de animais," que "nos terrenos onde se originam" a mata seria preservada e que "a água dos chafarizes só servirá para os usos mais urgentes." Desse modo, tornaram doravante proibido nas fontes, chafarizes, caixas e encanamentos "lavar roupas, utensílios, vasilhames e quaisquer objetos, [...] lançar imundices de qualquer espécie", ou "encostar porcadas", especialmente nas "nascentes dos mananciais", e até mesmo "tomar banho", ou "tirar água para fazer barro para muro e adobes."

Desde pelo menos Hipócrates (médico grego da Era Clássica, considerado pai da medicina ocidental), sabe-se que a qualidade da água é essencial para a saúde. Sua corrupção provoca inúmeras doenças e, por essa razão, não se podia mais, em nome da 
saúde pública, deixar a população usá-la sem restrições. Todo cuidado era pouco, pois ainda não havia opção eficaz e acessível para tratamento dos recursos hídricos, que começavam a ficar escassos e correndo grande perigo de contaminação com o surto de explosão demográfica em curso no espaço urbano do início do século XX.

Nesse mesmo campo de preocupação, outro alvo da atuação reformista da elite política local foram os dejetos residenciais. No dia 22 de janeiro de 1921, a Câmara autorizou "o agente executivo a fazer estudos necessários ao estabelecimento de rede de esgotos." Ainda estava vigente o costume, praticado nas aglomerações urbanas da época colonial, da conservação de barris, caixas ou latões e um determinado espaço da propriedade, onde era depositado o conteúdo dos urinóis, até serem completados e, depois disso, despejados nos rios ou nos matos.

Nada apropriada para a saúde pública, essa prática foi aos poucos desaparecendo do repertório dos hábitos cotidianos com o avanço das políticas sanitárias adotadas, no caso brasileiro, ainda na época do Império, e impulsionada ao longo da República. Em Alfenas, no dia 25 de janeiro de 1920, o seu legislativo, seguindo a tendência em curso nos centros atentos a essas questões, resolveu que "na cidade e nas demais zonas do município será obrigatória o uso de latrinas", sendo as "fossas protegidas contra moscas e ao abrigo das chuvas" que, conforme legislado, "não poderão receber senão até dois terços da sua capacidade, devendo ser enterradas." Além disso, sua abertura somente ocorrerá "depois da autorização das autoridades sanitárias, tendo-se em vista a natureza do terreno, a proximidade das habitações e a profundidade do lençol das águas subterrâneas."

Ao longo do tempo, os velhos urinóis deixaram de fazer parte do conjunto de utensílios domésticos. Não demorou muito para as redes de esgotos começarem a ser instaladas e, com elas, os banheiros equipados de vasos sanitários. Assim, lentamente, o país foi superando um velho obstáculo à saúde pública, que muitos danos provocaram à sua população, enquanto a cultura que determinava nossa maneira de lidar com nossos dejetos permanecia inerte (adaptada às limitações de uma época anterior ao movimento sanitarista e das novas tecnologias da engenharia civil).

Outro alvo da agenda reformista do legislativo municipal foram as condições dos locais de comercialização e transporte de alimentos. Em 1918, seus membros editaram algumas leis a esse respeito. A primeira delas, votada no dia 24 de janeiro de 1918, definiu o seguinte: "Todo açougue situado no perímetro urbano, que não reúna as condições de higiene exigidas pela Câmara, e não esteja de acordo com a planta oficial 
adotada, deve ser modificado dentro do prazo de 90 dias contados da notificação." Já no dia posterior ficou determinado que "o matadouro é o único local onde é permitido, dentro do perímetro urbano, abater-se gado de qualquer espécie" e que, daquele dia em diante, os animais ao darem entrada em tal estabelecimento deveriam "ser examinados pelo médico". Depois de abatidos, "o serviço de transporte das carnes para os açougues" passaria a ser "feito em carroças apropriadas, fechadas por venezianas e guiadas por empregados municipais" e, para garantir o asseio, elas deveriam ser "mantidas em rigoroso estado asséptico."

As feiras livres, que se realizam na quinta e nos domingos na Praça do Mercado, também estiveram na mira da autoridade governamental alfenense. No dia 9 de setembro de 1918, a Câmara local elaborou um regulamento para seu funcionamento. Entre as proibições regulamentadas, destacam-se: "entrarem no mercado ébrios, desordeiros e pessoas afetadas por moléstias contagiosas, cuspir no chão e expor à venda gêneros deteriorados."

Todos esses dados relativos ao asseio público mostram que a higiene foi, realmente, uma das preocupações maiores da reforma dos costumes promovidas pelas elites influenciadas pelo movimento sanitário nacional; movimento protagonizado por políticos e intelectuais progressistas, que teve por finalidade promover o saneamento do interior do país e, para isso, procurou em primeiro lugar alertar a nação da precariedade de suas condições sanitárias (HOCHMAN, 1998, p. 63). Alfenas pode ser considerada um exemplo de que esse alerta surtiu efeito, porque tinha uma elite política em cujo seio sobressaíram indivíduos, como João Leão de Faria (deputado estadual nos anos 1920 e criador, em 1914, de uma instituição superior de ensino de Farmácia e Odontologia, EFOA, convertida em universidade federal em 2005), que estavam sintonizados com o ideário sanitarista nacional.

Mas para o tipo de reforma acima proposto dar certo, há outro elemento fundamental: a educação, sem a qual toda medida tomada acaba sendo limitada. Assim, era necessário promover o ensino no país, porque, sem isso, conforme pertinente ponderação feita na época, "não seremos um povo são e forte, ao nível da civilização contemporânea, enquanto, analfabetos e não educados, ignorarmos os princípios da saúde física e da energia moral coletiva."

Em conformidade com esse ideário, a Câmara Municipal, entre outras medidas (como a aprovação de verba, em 1918, para ajudar a construir o novo prédio da Escola de Farmácia e Odontologia de Alfenas) instituiu "o prêmio de quinhentos mil réis para 
cada professor rural, cuja escola dista no mínimo dois quilômetros de escola pública, que apresente no fim de cada ano dez alunos sabendo ler, escrever e fazer as quatro operações." Além disso, anos mais tarde, no dia 27 de outubro de 1927, criou "o Ginásio Alfenas.”

O historiador tem a desvantagem de não poder observar os fenômenos humanos enquanto eles ocorrem, mas tem a vantagem de saber o seu desfecho no longo prazo quando está devidamente afastado no tempo para isso. $\mathrm{E}$ o que sabemos é que todo processo modernizador produz, dialeticamente, profundas contradições, principalmente em países situados na periferia do capitalismo. Ou seja, se por um lado há uma reatualização do autoritarismo, da exclusão social, das injustiças de todas as naturezas e da violência, por outro ocorreram algumas mudanças consideráveis, como na saúde pública. A esse respeito cabe lembrar que a reforma dos costumes, levada a cabo pelas elites hegemônicas do país durante nossa primeira experiência republicana, com base no ideário médico sanitarista, acabou promovendo melhorias inegáveis nas condições sanitárias da população em geral, apesar de algumas medidas terem sido adotadas com bastante truculência, como a campanha da vacinação obrigatória, que levou à Revolta da Vacina em 1904.

Enfim, não obstante as mazelas oriundas de um processo de modernização conservador, alguns resultados materiais positivos do esforço legislativo, despendido ao longo da Primeira República em Alfenas, podem ser mensurados. Em 1937, havia na sede do Município 556 casas, das quais 412 recebiam o fornecimento de energia elétrica, 396 tinham água encanada potável e 370 estavam ligadas à rede de esgoto. Ou seja, a cidade, embora ainda fosse um pequeno burgo rodeado por uma vasta área rural e dependente da agropecuária, apresentava no alvorecer do Estado Novo indicadores modernos consideráveis para os padrões da época.

O que se procurou mostrar neste artigo é que em municípios do vasto interior do país, distante dos grandes centros nacionais e dependentes essencialmente da agropecuária, como o de Alfenas, houve, também, um processo de modernização que, em escala geográfica menor, é uma expressão do que vinha ocorrendo no Ocidente desde a consolidação de uma nova consciência (definida como moderna, e fundamentada na ideologia do progresso) do papel do homem na construção do seu destino. Assim, em tal município, parte de suas elites, em sintonia com as transformações que vinham ocorrendo no Ocidente desde a aurora da modernidade, procuraram reestruturar a paisagem local e os costumes considerados (por elas) arcaicos 
de seus habitantes, como forma de adequá-lo, principalmente à cidade, às exigências de uma nova configuração histórica, cuja vanguarda ansiava pelo progresso. 


\section{REFERÊNCIAS}

ADORNO, Theodoro; HORKHEIMER, Max. Dialética do esclarecimento. Rio de Janeiro: Zahar, 1985.

BERMAN, Marshall. Tudo que é sólido se desmancha no ar. São Paulo: Cia das Letras, 1986.

BRAUDEL, Fernand. Gramática das civilizações. São Paulo: Martins Fontes, 1989.

BURKE, Peter. Uma história social do conhecimento: de Gutenberg a Diderot. Rio de Janeiro: Jorge Zahar, 2003.

BURKE, Peter. Cultura popular na Idade Moderna. São Paulo: Cia das Letras, 1995.

BURY, John. The ideia of progress. Honolulu: University Press of the Pacific, 2004.

CASSIRER, Ernest. A filosofia do Iluminismo. Campinas: Ed. Unicamp, 1994.

DIDEROT, Denis; D’ALEMBERT, Jean. Encyclopédie ou dictionnaire raisonné, des arts et des métiers. $2^{\mathrm{a}}$ ed. Lucques: Chez Vicent Giuntini, 1758.

ELIAS, Nobert. O processo civilizador: uma história dos costumes. Rio de Janeiro: Zahar, 1990,

EUGÊNIO, Alisson. Arautos do progresso: ideário médico sobre saúde pública no Brasil na época do Império. Bauru: Edusc, 2012.

FURTADO, Celso. Formação econômica do Brasil. 27 ed., São Paulo: Cia Nacional/Publifolha, 2000.

GEERTZ, Clifford. A interpretação das culturas. Rio de Janeiro: Jorge Zahar, 1978.

GUMBRECHT, Hans Uricch. Making sense in life and liretature, theory and history. Mineapolis: University of Minesota Press, 1992.

GUSDORF, Georges. Dieu, la nature, l'homme au siécle des lumiéres. Paris: Payot, 1972.

HABERMAS, Jürgen. O discurso filosófico da modernidade. São Paulo: Martins Fontes, 2002.

HAZARD, Paul. O pensamento europeu no século XVIII. Lisboa: Editorial Presença, 1973.

HELLER, Agnes. Uma crise global da civilização: os desafios futuros. In: HELLER, Agnes et al. A crise dos paradigmas em ciências sociais e os desafios para o século XXI. Rio de Janeiro: Contraponto, 1999.

HELLER, Agnes. O cotidiano e a história. 2 ed. Rio de Janeiro: Paz e Terra, 1985. 
HOBSBAWN, Eric. A era das revoluções. 17 ed. Rio de Janeiro: Paz e Terra, 2003.

HOCHMAN, Gilberto. A era do saneamento. São Paulo: Hucitec, 1998.

JANOTTI, Maria de Lourdes Mônaco. Sociedade e Política na Primeira República. São Paulo: Atual, 1999.

LENHARO, Alcir. As tropas da moderação o abastecimento da corte na formação política do Brasil, 1808-1842. São Paulo, Símbolo, 1979.

SAES, Alexandre Macchione et al. O sul de Minas em transição: a formação do capitalismo na passagem para o século 20. Bauru: Edusc, 2012.

NISBET, Robert. History of ideia of progress. New York: Transaction Publishers, 1980.

PINTO, Surama Condé. O jogo político na antiga capital federal. Rio de Janeiro: Mauad X, 2011.

PRADO Jr., Caio. História econômica do Brasil. 42 ed., São Paulo: Brasiliense, 1995.

SEVCENKO, Nicolau. Orfeu estático na metrópole: São Paulo, sociedade e cultura nos frementes anos 20. São Paulo: Cia das Letras, 1992.

VISCARDI, Cláudia. O teatro das oligarquias: uma revisão da "política do café com leite". Belo Horizonte: Fino Traço, 2012. 